Bolton, M. J., L. K. Ault, D. M. Greenberg. and S. Baron-Cohen, 2018: Exploring the human side of meteorology:

a brief report on the psychology of meteorologists. J. Operational Meteor., 6 (3), 23-32,

doi: https://doi.org/10.15191/nwajom.2018.0603

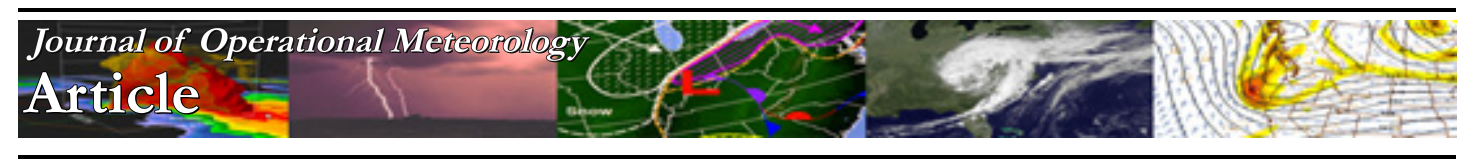

\title{
Exploring the Human Side of Meteorology: A Brief Report on the Psychology of Meteorologists
}

\author{
MATTHEW J. BOLTON AND LARA K. AULT \\ Saint Leo University, School of Arts and Sciences, Saint Leo, FL \\ DAVID M. GREENBERG AND SIMON BARON-COHEN \\ Autism Research Centre, Department of Psychiatry, University of Cambridge, Cambridge, U.K.
}

(Manuscript received 21 October 2017; review completed 16 March 2018)

\begin{abstract}
Links between autism spectrum conditions and scientific aptitude were first investigated twenty years ago. Since then, associations between autism and STEM (science, technology, engineering, and math) aptitude have been established and discussed via the empathizing-systemizing (E-S) theory. E-S theory hypothesizes that autistic individuals are naturally driven to create and analyze sets of logical rules, or "systems," related to and constructed around things in the world. This is at the expense of cognitive, but not affective, empathy. Here, we not only extend previous work in testing the similarity of meteorologists, engineers, and physicists with respect to empathizing, systemizing, and autistic traits; we also report the first examination of meteorologists' personality and mental health relative to other representative physical scientists. Meteorologists in this sample were higher in empathizing and systemizing, extraversion, conscientiousness, and agreeableness, and less stressed, depressed, and anxious, than were engineers and physicists. Implications for the meteorological workplace are discussed.
\end{abstract}

\section{Introduction}

Meteorologists not only study the weather, but also its intersection with society. This includes perceptions of forecast uncertainty (Handmer and Proudley 2007; Joslyn and Savelli 2010; Morss, Demuth, and Lazo 2008), perceptions of weather risk and severe weather lead time (Hoekstra et al. 2011), the psychological importance of weather (Stewart 2009; Stewart et al. 2012), beliefs about and perceptions of climate change (Egan and Mullin 2012; Hamilton and Stampone 2013; Taylor, de Bruin, and Dessai 2014), public health and weather messaging (Williams and Grundstein 2017; Williams et al. 2017), the relationship between perception of color and the communication of weather information (Bryant et al. 2014), the role weather itself plays in influencing mental health (Bulbena et al 2005; Coleman et al. 2014; Greening and Dollinger 1992; Lonigan et al. 1994; Matthey 1988; Westefield et al.
2006; Wang 2000), and even meteorologists' use of weather data and cognitive performance in forecasting (Bowden et al. 2015; Bowden and Heinselman 2016; Wilson et al. 2016; Heinselman et al. 2015). Considering past research into the relationship between autism and science, and the multitude of work-related psychological stressors meteorologists often face, it is surprising that more work has not examined the psychology of meteorologists themselves. Here, we test potential links between the field of meteorology, autism, mental health, and personality.

\section{a. Study rationale}

With the "always-on" nature of the meteorological profession (which involves 'round-the-clock forecasting, rotating shiftwork, and long hours, among other job requirements), it is important to talk about potential work-related mental health issues in the field. 
This is because poor workplace mental health across various disciplines has been found to have far-reaching repercussions such as absenteeism, labor turnover, and loss of productivity (Palmer and Dryden 1994), lower self-esteem, poor family life, and conditions like heart disease (Goodspeed and DeLucia 1990).

Considering these and other factors, we were driven by curiosity to investigate possible moderating effects of personality on aspects of mental health (depression, anxiety, and stress). That is, do the personality traits that attract people to meteorology grant those individuals some inherent element of fortitude and psychological "grit" in their demanding profession?

\section{b. Personality theory}

Whereas mood is akin to weather in the way that it frequently changes, personality can be likened to climate, being a set of sustaining behavioral characteristics that serve as a good long-term indicator of an individual's psychological disposition. Ideas fostered by the likes of Galton ${ }^{1}$ and by Cattell (1957), among others, led to the Five Factor Model of personality we recognize today (McCrae and Costa 1987). The five personality traits of openness, conscientiousness, extraversion, agreeableness, and neuroticism-found to be stable across cultures, linked to genetics, and fairly stable across the lifespan, with most fluctuation in childhood and adolescence-may be readily remembered with the O.C.E.A.N. acronym. Openness refers to an individual's curiosity, creativity, and preference for experiencing variety in daily life. Conscientiousness can be thought of as the tendency for dependability and action with regard to duty, to plan and organize, and to enforce selfdiscipline. Extraversion is essentially one's tendency for sociability; it refers to social energy and positivity, to the tendency to seek social stimulation. Agreeableness is a tendency for compassion and cooperation with others. Neuroticism, finally, refers to one's emotional stability, impulse control ability, and disposition for such negative emotions as anger, anxiety, or depression.

\footnotetext{
${ }^{1}$ Sir Francis Galton (1822-1911) was one of the earliest recognized modern psychologists and statisticians - creator of the concepts of statistical correlation and regression (Rushton 1990) and pioneer of early personality theory (Galton 1865; Goldberg 1993; Rushton 1990) - and the meteorologist credited with the discovery of anticyclonic flow and the first depiction of an upper air chart. See galton.org/ meteorologist.html and galton.org/books/meteorographica/index. $\underline{\mathrm{htm}}$ for more on his meteorological contributions.
}

\section{c. Autism and cognitive style}

Autism spectrum conditions (ASC or autism hereafter) affect individuals' neurological development and functioning. Autism occurs in 1 in 59 individuals in the United States (U.S. Centers for Disease Control 2018) and is characterized by difficulties in social communication alongside unusually narrow interests and repetitive behaviors, and sensory sensitivities (American Psychiatric Association 2013).

The empathizing-systemizing (E-S) theory accounts for the social and non-social behaviors of autism, the latter of which includes a need for sameness and attention to detail (Baron-Cohen 2009). E-S theory states that autistic individuals are inherently stronger at "systemizing" than they are empathizing. Empathy is defined cognitively, as the ability to imagine other people's mental states (their thoughts, intentions, desires, and feelings), and affectively, as the ability to respond to that person's mental state with an appropriate emotion. Systemizing is conversely defined as (1) the drive to create and analyze psychological sets of logical rules, or "systems," related to and constructed around things that occur in the world, and (2) the ability to intuit how systems work in the physical world. Systemizing as a psychological process entails identifying lawful regularities in physical and other systems that involve an operation-an action-resulting in reliable output. Hence, any information that is lawful may be systemized. There are six main types of systems (Baron-Cohen 2003)-abstract (e.g., mathematics), mechanical (e.g., a bicycle), natural (e.g., the weather), collectible (e.g., a library), motoric (e.g., a golf-swing), and social (e.g., a military unit). Autistic individuals are thought to be naturally driven to seek truth-a concept defined here as "precise, reliable, consistent, or lawful patterns or structure in [some kind of] data" (BaronCohen 2008)-through psychological system-building. Systems are analyzed and built through the observation of some individual detail (variable) of a system, and then by the subsequent monitoring of the overall system for a lawful change following manipulation of the individual variable. Systemizing is also purposeful, by the manipulation of a given variable, in the framework of "if I do X, A changes to B. If Z occurs, $\mathrm{P}$ changes to Q" (Baron-Cohen 2008).

The concept of hyper-systemizing attempts to explain the repetitive behaviors often observed across ASCs (e.g., young children spinning wheels on toy cars, fascination with dates, arranging objects in sequences, 
the need for routine, structure, and sameness) and the tendency for autistic individuals to be disinterested in socializing. The higher one's tendency for systemizing, the less inclined that person typically is toward socializing. This is because as one becomes more oriented towards systemizing, the need for systems of lower variance increases (Baron-Cohen 2003). The social world, driven by emotions, is far less lawful than domains that include spinning objects or record keeping (Baron-Cohen 2008).

Empathizing and systemizing are thought to exist as distinct cognitive styles (frameworks for the way people think, gather, process, use, and remember information; Sarmany-Schuller 1987), along normative bell curves: at one end people are strongest in empathic expression, while at the other are those strongest in systemizing ability. Although people tend to align more with one cognitive style or the other, some individuals are relatively balanced in their empathizing and systemizing abilities (Baron-Cohen 2003). Autistic individuals demonstrate superiority in systemizing when compared to those without autism (Baron-Cohen et al. 2003). Systemizing, further, is typically expressed more highly in men than in women (Baron-Cohen 2003).

Systemizing may cause a predisposition for talent in fields that involve high degrees of pattern recognition and attention to detail (Baron-Cohen et al. 2009), like STEM (science, technology, engineering, and mathematics). There are previously established links between autism and STEM (Baron-Cohen et al. 1997, 1998, 1999, 2001, 2007; Roelfsema et al. 2012; Ruzich et al. 2015). Based on these linkages, we investigated the presentation of autistic traits, empathy, and systemizing in meteorologists relative to engineers and physicists. Systems in physics and engineering operate with enormous regularity, while meteorological systems (physical or psychological) inherently involve more variability. Our aims in this area were threefold: to determine if there exists either distinct group difference or mere similarity between meteorologists and other physical scientists; to test, for the first time, meteorologists' autistic trait tendencies, in order to determine the extent of autism-weather links; and to test whether meteorologists have a cognitive style more slanted towards systemizing than empathizing.

\section{Data and methods}

\section{a. Participants}

Participants $(N=327)$ were college student $(n=160$, $48.9 \%)$ and college-graduated, workforce-employed, adults $(n=167,51.1 \%)$ in the physical $(n=279)$ and social sciences $(n=26)$, and the humanities $(n=22)$. Males constituted the majority of the sample $(65.4 \%, n$ $=214$, with $34.6 \%$ identifying as female, $n=113$ ). One individual identifying as nonbinary (neither male nor female) was excluded from analyses, as that person was the only participant to identify as such. Racially, the sample was comprised primarily of Caucasian/white individuals $(n=273,83.5 \%)$. The remaining participants were Asian $(n=13,4.0 \%)$, African-American/black $(n=9,2.8 \%)$, Hispanic $(n=9,2.8 \%)$, Latino/a $(n=$ $8,2.4 \%)$, bi- or multi-racial $(n=8,2.4 \%)$, or other $(n$ $=6,1.8 \%$ ). Only participants who fully reported age, gender, student status, and occupation were included for analyses. We collected age brackets rather than exact ages. There were 275 participants between the ages of 18 and 44; the remaining 52 were 45 or older. We compared meteorologists $(n=157)$, engineers $(n=$ $64)$, and physicists $(n=57)$. Our meteorologist sample was smaller than hoped for. However, the employment data available for $128(81.52 \%)$ of these individuals indicates a fairly well-rounded representation of each of the employment sectors of the American weather community relative to the sample: 32 television/media meteorologists (broadcasters, hereafter), 46 National Weather Service (NWS) employees, 18 in the private sector, 16 in academia, and 8 who were employed in a non-NWS operational forecasting capacity; 2 were employed outside of the United States, and 6 were in a capacity not listed. Because of their much smaller size relative to our physical scientist group, and because most other work on physical scientists and autism focused primarily on comparison with them, we ultimately chose to exclude from our analyses participants in the social sciences and humanities.

\section{b. Procedure}

An online Qualtrics survey was distributed via social media, email to members of the National Weather Association and American Meteorological Society, and via the Cambridge Autism Research Database (at www.autismresearchcentre.com and www. cambridgepsychology.com). Given this distribution 
method, the sample was largely one of convenience. Participants completed several individual difference measures, all approved by the Saint Leo University research ethics board. Measures included the AutismSpectrum Quotient (AQ; Baron-Cohen et al. 2001) to assess participants' autistic trait levels, the Empathy Quotient (EQ; Baron-Cohen and Wheelwright 2004) to measure empathic expression, the Systemizing Quotient-Revised (SQ-R; Wheelwright et al. 2006) to measure systemizing tendency, the Big Five InventoryShort (BFI-S; Lang et al. 2011) to measure personality, and the 21-item version of the Depression, Anxiety, and Stress Scales (DASS; Lovibond and Lovibond 1995) to measure three aspects of mental health. Please see Appendix A for descriptions of these psychological tests, and information relating to their psychometric properties.

\section{Results and discussion}

Multiple analysis of variance (MANOVA), a statistical test assessing the effects of multiple independent variables on multiple dependent variables, drastically decreased our sample size in comparing meteorologists, engineers, and physicists separately (such that our group sizes were widely disparate and also not representative of the overall sample). We therefore combined the engineer and physicist populations into one group for a more robust comparison with the larger meteorologist population.

Welch's analysis of variance (ANOVA), a test which examines the effect of independent variables on one dependent variable, was conducted instead to test differences between science domains, including differences between male and female expressions of empathy, systemizing, and autistic traits, and comparisons of personality and mental health (depression, anxiety, and stress) across science domains. Welch's ANOVA was chosen following recent recommendations (Delacre et al. 2018) that the test be used in place of the regular $F$-test-based oneway ANOVA. For these, we calculated effect size (eta-squared, $\eta p^{2}$ ), and statistical power. Effect sizes, ranging from 0 to 1 , measure the amount of standardized difference between means (Levine and Hullett 2002), while power is a measure, also ranging from 0 to 1 , that represents the probability of correctly rejecting the study's null hypothesis (Boslaugh 2012, p. 375).

The group differences in empathizing and systemizing (shown in Tables 1 and 2) were statistically significant and nonsignificant (empathizing $p=.046$, $\eta p^{2}=0.02$, power $=0.06$; systemizing $p=.411, \eta p^{2}=$ 0.003 , power $=0.05$ respectively), with meteorologists reporting higher tendencies for both traits compared to the study's combined engineers and physicists. Meanwhile, the engineers and physicists reported significantly higher autistic trait amounts, $(p=0.005$, $\eta p^{2}=0.03$, power $=0.08$ ).

The physical scientists as a whole scored comparably on the AQ to STEM groups in other work (Baron-Cohen et al. 2001; Ruzich et al. 2015). In this sample, meteorologists were the strongest systemizers, when compared to physicists and engineers combined; in a pure between-groups comparison of means (nonstatistical, see Table 1), they were second, behind the study's physics-oriented participants. This is not overly surprising, given the past work on physical scientists. It is interesting, however, that meteorologists additionally had the highest group tendency for empathic expression (with a mean EQ score not far off those reported by participants in the social sciences and humanities in 2006 work by Wheelwright and colleagues). Given the meteorological profession's orientation toward public service, this finding makes sense and perhaps suggests a balancing of the E-S cognitive profiles within meteorologists. This warrants further investigation.

In terms of sex differences, men were significantly more expressive of systemizing, Welch's $F(1,191.77)$ $=31.99, p<0.001\left(M_{\text {Men }}=70.13, S D=20.92 ; M_{\text {Women }}=\right.$ $55.06, S D=19.91), \eta p^{2}=0.11$, power $=0.41$, and autistic traits, Welch's $F(1,184.40)=4.01, p=0.032$ $\left(M_{\mathrm{Men}}=21.35, S D=6.86 ; M_{\text {Women }}=19.50, S D=7.78\right), \eta p^{2}$ $=0.01$, power $=0.05$, while women were significantly more empathic, Welch's $F(1,145.02)=4.68, p=$ 0.032, $\left(M_{\text {Men }}=37.07, S D=11.80 ; M_{\text {Women }}=41.17, S D=\right.$ $15.71), \eta p^{2}=0.02$, power $=0.06$. These sex differences replicated past studies in which men were found to be more expressive of autistic traits and systemizing and women higher in empathizing (Baron-Cohen et al. 2001; Baron-Cohen et al. 2003; Billington et al. 2007).

Insofar as group personality differences are concerned (see Table 3), meteorologists were significantly more agreeable, $\left(p=0.004, \eta p^{2}=0.03\right.$, power $=0.08)$; conscientious, $\left(p<0.001, \eta p^{2}=0.07\right.$, power $=0.21)$; and extraverted $\left(p<.001, \eta p^{2}=0.04\right.$, power $=0.10)$. In contrast, engineers and physicists were significantly more neurotic $\left(p=0.004, \eta p^{2}=0.03\right.$, power $=0.08)$ and non-significantly more open, $(p=$ $0.132, \eta p^{2}=0.008$, power $=0.05$ ). 
Table 1. Tendencies by group for autistic traits, empathizing, and systemizing. Data shown are group means and standard deviations (in parentheses). Top scoring group for each variable is bolded. Click image for an external version; this applies to all tables hereafter.

\begin{tabular}{|c|c|c|c|}
\hline & Autistic Traits & Empathizing & Systemizing \\
\hline Meteorologists & $20.08(6.91)$ & $\mathbf{3 8 . 7 8 ( 1 3 . 4 2 )}$ & $67.69(21.35)$ \\
\hline Engineers & $22.26(8.40)$ & $36.18(14.40)$ & $62.77(23.01)$ \\
\hline Physicists & $\mathbf{2 3 . 1 9 ( 6 . 4 2 )}$ & $34.05(10.35)$ & $\mathbf{6 7 . 8 5 ( 2 0 . 9 5 )}$ \\
\hline All Combined & $21.16(7.26)$ & $37.38(13.21)$ & $66.73(21.61)$ \\
\hline
\end{tabular}

Table 2. Meteorologists' autistic traits, empathy, and systemizing compared to combined engineers and physicists. Data shown are group means and standard deviations (in parentheses). Top scoring group for each variable is bolded.

\begin{tabular}{|c|c|c|c|}
\hline & Autistic Traits & Empathizing & Systemizing \\
\hline Meteorologists & $20.08(6.91)$ & $\mathbf{3 8 . 7 8 ( 1 3 . 4 2 )}$ & $\mathbf{6 7 . 6 9 ( 2 1 . 3 5 )}$ \\
\hline Other Physical Scientists & $\mathbf{2 2 . 7 0 ( 7 . 5 0 )}$ & $35.18(12.63)$ & $66.73(21.61)$ \\
\hline
\end{tabular}

Table 3. Meteorologists' personality traits compared to combined engineers and physicists. Data shown are group means and standard deviations (in parentheses). Top scoring group for each variable is bolded.

\begin{tabular}{|c|c|c|c|c|c|}
\hline & Openness & Conscientiousness & Extraversion & Agreeableness & Neuroticism \\
\hline Meteorologists & $14.38(3.46)$ & $\mathbf{1 1 . 6 6 ( 1 . 9 3 )}$ & $\mathbf{1 1 . 4 5 ( 4 . 6 2 )}$ & $\mathbf{1 0 . 6 9 ( 1 . 7 0 )}$ & $9.63(3.36)$ \\
\hline $\begin{array}{c}\text { Other Physical } \\
\text { Scientists }\end{array}$ & $\mathbf{1 5 . 0 1 ( 3 . 3 1 )}$ & $10.46(2.61)$ & $9.69(4.19)$ & $10.01(2.04)$ & $\mathbf{1 1 . 0 7 ( 4 . 2 7 )}$ \\
\hline
\end{tabular}

Table 4. Meteorologists' depression, stress, and anxiety compared to combined engineers and physicists. Data shown are group means and standard deviations (in parentheses). Top scoring group for each variable is bolded.

\begin{tabular}{|c|c|c|c|}
\hline & Depression & Anxiety & Stress \\
\hline Meteorologists & $11.05(3.97)$ & $10.57(3.26)$ & $13.55(4.44)$ \\
\hline Other Physical Scientists & $\mathbf{1 5 . 5 7 ( 6 . 7 6 )}$ & $\mathbf{1 3 . 4 0 ( 5 . 6 2 )}$ & $\mathbf{1 6 . 6 8 ( 6 . 7 4 )}$ \\
\hline
\end{tabular}

As shown in Table 4, meteorologists reported lower scores across all three measured dimensions of mental health. Engineers and physicists were significantly more depressed $\left(p<0.001, \eta p^{2}=0.14\right.$, power $\left.=.63\right)$; anxious $\left(p<.001, \eta p^{2}=0.10\right.$, power $\left.=0.37\right)$; and stressed, $\left(p<.001, \eta p^{2}=0.07\right.$, power $\left.=0.21\right)$. Although further investigation is needed, personality traits do, indeed, appear to temper meteorologists' group disposition for depression, anxiety, and stress. This is supported by other work on the relationship between personality and subjective wellbeing/mental health (Steel et al. 2008).

Our results preliminarily support the statement that meteorologists are similar to other physical scientists, in terms of systemizing and autistic traits. They differ from engineers and physicists by virtue of their more pronounced tendencies for empathic expression, and in their relatively stable mental health trends. Compared to physical scientist groups otherwise like themselves (in terms of autistic traits and systemizing ability), the meteorologists we sampled were significantly less depressed, anxious, and stressed, and expressed significantly greater tendencies for agreeableness, conscientiousness, and extraversion. Meteorology's nature as a service-oriented field may moderate this relationship in some way, as agreeableness, conscientiousness, and extraversion could all enhance the meteorologist's sense of teamwork on the job, and also their sense of need to inform the public about severe and dangerous weather. This supposition, fueled by anecdotal discussions with meteorologists corroborating empathy as a core part of the profession, warrants future work. We, through personal communication with meteorologists, were relayed information about forecaster feelings related to severe weather events as far back as some thirty years in the past. This discussion revealed lingering feelings of guilt and concern for people who were killed or otherwise adversely affected in severe weather situations for which the meteorologists in question provided forecast support. Others, recently, were similarly affected by the catastrophic impact of Hurricane Harvey's copious and widespread flooding in Texas, and by the impacts of Hurricanes Irma and Maria 
in Florida and Puerto Rico. Tables 5, 6, and 7 show the various intragroup differences among meteorologists, in depression, anxiety, and stress; autistic traits, empathizing, systemizing; and personality traits, respectively.

\section{Limitations}

A small sample size restricted our ability to compare meteorologists more fully to engineers and physicists, separately. Much of this work therefore warrants attempt at replication. Moreover, caution in overgeneralizing these results to other countries is advised, because of the way meteorological methodologies differ country-to-country. Finally, as this was a selfreport study, it involves all the typical limitations of self-report, including honesty of responses and other impression management concerns, participants' attention to or understanding of questions, and accuracy of self-awareness when responding. Another limitation lies in our survey's distribution strategy: That is, the sample may have incurred a selection bias because most participants were recruited via professional societies. These individuals may be inherently more extraverted; future work in this area should utilize a broader sampling strategy (e.g., distribution via e-mailing lists) to mitigate the introduction of such potential biases.

\section{Conclusions}

This study provided a novel investigation of meteorologists' tendencies for empathizing, systemizing, and autistic traits, and explored trends in group mental health and personality. We did not observe total similarity between meteorologists and other physical scientists due to our meteorologists' pronounced tendency for empathy; however, they were found to be strong systemizers nonetheless. This builds upon previous work linking autism and physical scientists, and provides further evidence for E-S theory. Additionally, beyond validation of existing psychological theory and original contribution to the psychological literature (regarding the personality and mental health of physical scientists), this work provides an important step in examining meteorologists' overall mental makeup. Alongside planned future work, these results will allow meteorological employers a baseline by which to potentially gauge their employees' on-job mental health. Future work will focus on subjective wellbeing with an in-depth examination of tendencies for such things as on-job burnout and resilience in the face of providing forecasts for dangerous weather events involving fatalities. We hope this article proves valuable in raising awareness for mental health issues in meteorology and helps to convey the importance of destigmatizing and openly discussing mental health; even simply discussing these topics among peers has been shown to improve mental health (Davison et al. 2000; Vogel et al. 2007). Encouragingly, we are beginning to see meteorological professionals doing exactly this (Milrad 2016; Zee 2017; The Weather Junkies 2018; DePodwin 2018).

Acknowledgments: We are grateful to Janice Bunting at the National Weather Association, Kelly Savoie at the American Meteorological Society, and Paula Smith at the Autism Research Centre, Cambridge, for distributing our survey. We are also grateful to two anonymous reviewers whose comments greatly strengthened the final manuscript. SB-C was supported by the Autism Research Trust and the Medical Research Council during the period of this work. The research was supported by the National Institute for Health Research (NIHR) Collaboration for Leadership in Applied Health Research, Care East of England at Cambridgeshire, and Peterborough NHS Foundation Trust. The views expressed are those of the authors and not necessarily those of the NHS, the NIHR, or the Department of Health. MJB conceived and designed the study under the supervision of LKA and with the advice of SB-C, and collected and analyzed the data with analysis assistance from DMG. All authors contributed to the paper (MJB LKA DMG SB-C) and approved the final draft. The authors declare no conflict of interest.

\section{APPENDIX A: Description of Measures}

The following psychological measures were used in this study. For each, we calculated Cronbach's coefficient alpha $(\alpha)$. This statistic, ranging from 0 to 1 , estimates how internally consistent validated scale items are; that is, how well they assess the construct they were designed to measure (Cronbach 1951). We followed Lodder's (2013) recommendation to compute the mean score for responses with fewer than $10 \%$ missing data.

The Autism-Spectrum Quotient (AQ). Items are 50 statements about one's tendencies in the areas of social skills, routine, attention-switching, imagination, and numbers and patterns. Higher scores indicate more autistic traits. The AQ scores were found to be adequately reliable, with Cronbach's $\alpha$ equaling 0.79 . 
Table 5. Meteorologist subgroup tendencies for depression, anxiety, and stress. Data shown are group means and standard deviations (in parentheses). Top scoring group for each variable is bolded.

\begin{tabular}{|c|c|c|c|}
\hline & Depression & Anxiety & Stress \\
\hline NWS & $11.48(4.03)$ & $\mathbf{1 0 . 9 6 ( 3 . 4 9 )}$ & $14.35(5.16)$ \\
\hline Broadcasters & $11.23(5.14)$ & $10.65(3.51)$ & $13.71(4.07)$ \\
\hline Private Sector & $10.87(4.03)$ & $10.67(2.90)$ & $13.53(3.66)$ \\
\hline Academia & $10.94(3.66)$ & $10.50(3.67)$ & $12.13(2.73)$ \\
\hline Non-NWS Operational & $\mathbf{1 1 . 6 3 ( 4 . 3 7 )}$ & $9.00(1.07)$ & $\mathbf{1 5 . 0 0 ( 4 . 8 4 )}$ \\
\hline
\end{tabular}

Table 6. Meteorologist subgroup tendencies for autistic traits, empathizing, and systemizing. Data shown are group means and standard deviations (in parentheses). Top scoring group for each variable is bolded.

\begin{tabular}{|c|c|c|c|}
\hline & Autistic Traits & Empathizing & Systemizing \\
\hline NWS & $\mathbf{2 1 . 5 0 ( 7 . 5 2 )}$ & $35.86(14.64)$ & $66.53(17.66)$ \\
\hline Broadcasters & $18.07(5.88)$ & $\mathbf{4 1 . 1 6 ( 1 2 . 0 1 )}$ & $68.62(24.46)$ \\
\hline Private Sector & $19.07(5.34)$ & $39.58(9.40)$ & $71.50(18.04)$ \\
\hline Academia & $20.50(7.13)$ & $40.56(16.30)$ & $73.00(19.33)$ \\
\hline Non-NWS Operational & $20.88(5.59)$ & $36.88(9.13)$ & $\mathbf{7 6 . 7 5 ( 1 4 . 6 0 )}$ \\
\hline
\end{tabular}

Table 7. Meteorologist subgroup tendencies for personality traits. Data shown are group means and standard deviations (in parentheses). Top scoring group for each variable is bolded.

\begin{tabular}{|c|c|c|c|c|c|}
\hline & Openness & Conscientiousness & Extraversion & Agreeableness & Neuroticism \\
\hline NWS & $14.07(3.72)$ & $\mathbf{1 2 . 1 7 ( 1 . 7 8 )}$ & $10.33(4.00)$ & $10.43(1.64)$ & $\mathbf{1 0 . 1 1 ( 2 . 9 6 )}$ \\
\hline Broadcasters & $15.13(3.16)$ & $11.88(1.56)$ & $12.56(4.93)$ & $10.47(2.03)$ & $9.56(2.96)$ \\
\hline Private Sector & $\mathbf{1 5 . 4 4 ( 3 . 2 0 )}$ & $11.44(2.07)$ & $\mathbf{1 2 . 7 5 ( 5 . 0 0 )}$ & $\mathbf{1 1 . 0 0 ( 1 . 3 8 )}$ & $9.25(3.04)$ \\
\hline Academia & $14.56(3.93)$ & $11.00(2.03)$ & $10.25(4.52)$ & $10.94(1.24)$ & $9.19(3.78)$ \\
\hline Non-NWS Operational & $14.50(3.93)$ & $11.25(1.75)$ & $11.38(5.90)$ & $10.88(1.73)$ & $9.63(3.70)$ \\
\hline
\end{tabular}

The Empathy Quotient (EQ). The 40-item EQ measures an individual's tendencies for cognitive and affective empathy. One point is tallied if the respondent records the empathic behavior in each item mildly; if the respondent records the behavior strongly, they are given two points. The EQ scores were highly reliable in this study, with Cronbach's $\alpha$ equaling .90 .

The Systemizing Quotient-Revised (SQ-R). The 75item Systemizing Quotient was designed to assess an individual's interest in systems across different types of system. An individual scores two points for strong endorsement of the systemizing-oriented response, and one point for slight endorsement of the systemizing response. The SQ-R scores, like those of the EQ, were highly reliable, with an $\alpha$ of 0.91 .

Big Five Inventory - Short (BFI-S). The BFI-S is a short instrument designed to measure the Big Five personality factors in large surveys. Within the BFI-S, each of the five personality factors - openness, conscientiousness, extraversion, agreeableness, and neuroticism-is measured with three items on a sevenpoint Likert scale from one (strongly disagree) to seven (strongly agree). Higher scores for a particular trait equates to a more prominent expression of that trait within the responding individual. The BFI-S scores were found to have poor internal reliability (Cronbach's $\alpha$ of 0.34 ). This is likely due to the breadth of the psychological constructs in question and their being measured so briefly (as noted by Lang et al. 2011), as consistency is partially reliant on length of the scale being measured (Nunnally 1970).

Depression, Anxiety, and Stress Scales, 21-items (DASS21). The DASS was designed to measure the three related negative emotional states of depression, anxiety, and stress/tension. Each emotional state is allocated seven items, totaling 21 items scored on a four-point scale ranging from 0 through 3 . Higher scores are indicative of higher trait levels. The DASS21 scores were highly reliable, with an $\alpha$ of 0.93 .

\section{REFERENCES}

American Psychiatric Association, 2013: Autism Spectrum Disorder. Diagnostic and Statistical Manual of Mental Disorders: DSM-5. Amer. Psychiatric Assoc., 50-59.

Baron-Cohen, S., 2003: The Essential Difference: Men, Women and the Extreme Male Brain. Penguin/Basic Books. 
Baron-Cohen, S., 2006: The hyper-systemizing, assortative mating theory of autism. Prog. Neuropsychopharmacol. Biol. Psychiatry, 30, 865-872, Crossref.

Baron-Cohen, S., 2008: Autism, hypersystemizing, and truth. Quart. J. Exper. Psychol., 61, 64-75, Crossref.

Baron-Cohen, S., 2009: Autism: The empathizingsystemizing (E-S) theory. Annals NY Acad. Sci., 1156, 68-80, Crossref.

Baron-Cohen, S., and S. Wheelwright, 2004: The Empathy Quotient: An investigation of adults with Asperger Syndrome or high functioning autism, and normal sex differences. J. Autism Dev. Disord., 34, 163-175, Crossref.

Baron-Cohen, S., S. Wheelwright, C. Stott, P. Bolton, and I. Goodyer, 1997: Is there a link between engineering and autism? Autism, 1, 101-109, Crossref.

Baron-Cohen, S., P. Bolton, S. Wheelwright, V. Scahill, L. Short, G. Mead, and A. Smith, 1998: Does autism occur more often in families of physicists, engineers, and mathematicians? Autism, 2, 296-301, Crossref.

Baron-Cohen, S., S. Wheelwright, V. Stone, and M. Rutherford, 1999: A mathematician, a physicist, and a computer scientist with Asperger Syndrome: Performance on folk psychology and folk physics tests. Neurocase, 5, 475-483, Crossref.

Baron-Cohen, S., S. Wheelwright, R. Skinner, J. Martin, and E. Clubley, 2001: The Autism Spectrum Quotient (AQ): Evidence from Asperger Syndrome/high functioning autism, males and females, scientists and mathematicians. J. Autism Dev. Disord., 31, 5-17, Crossref.

Baron-Cohen, S., S. Wheelwright, V. Scahill, A. Spong, and J. Lawson, 2001: Studies of theory of mind: Are intuitive physics and intuitive psychology independent? J. Dev. Learn. Disord., 5, 47-78.

Baron-Cohen, S., J. Richler, D. Bisarya, N. Gurunathan, and S. Wheelwright, 2003: The Systemizing Quotient: An investigation of adults with Asperger Syndrome or high-functioning autism, and normal sex differences. Philos. Trans. R. Soc. Lond. B, 358, 361-374. Crossref.

Baron-Cohen, S., S. Wheelwright, A. Burtenshaw, and E. Hobson, 2007: Mathematical talent is linked to autism. Hum Nat., 18, 125-131, Crossref.

Baron-Cohen, S., E. Ashwin, C. Ashwin, T. Tavassoli, and B. Chakrabarti, 2009: Talent in autism: Hypersystemizing, hyper-attention to detail and sensory hypersensitivity. Philos. Trans. R. Soc. Lond. B Biol. Sci., 364, 1377-1383, Crossref.

Billington, J., S. Baron-Cohen, and S. Wheelwright, 2007: Cognitive style predicts entry into physical sciences and humanities: Questionnaire and performance tests of empathy and systemizing. Learn. Ind. Differ., 17, 260268, Crossref.
Boslaugh, S., 2012: Power analysis. Statistics in a nutshell: A desktop quick reference (second edition). O'Reilly Media Inc., 375 pgs.

Bowden, K. A., and P. L. Heinselman, 2016: A qualitative analysis of NWS forecasters' use of phased-array radar data during severe hail and wind events. Wea. Forecasting, 31, 43-55, Crossref.

Bowden, K. A., P. L. Heinselman, D. M. Kingfield, and R. P. Thomas, 2015: Impacts of phased-array radar data on forecaster performance during severe hail and wind events. Wea. Forecasting, 30, 389-404, Crossref.

Bryant, B., M. Holiner, R. Kroot, K. Sherman-Morris, W. B. Smylie, L. Stryjewski, M. Thomas, and C. I. Williams, 2014: Usage of color scales on radar maps. J. Oper. Meteor., 2, 169-179, Crossref.

Bulbena, A., G. Pailhez, R. Aceña, J. Cunillera, A. Rius, C. Garcia-Ribera, J. Gutierrez, and C. Rojo, 2005: Panic anxiety, under the weather? Int. J. Biomet., 49, 238-243, Crossref.

Cattell, R. B., 1957: Personality and Motivation Structure and Measurement. World Book.

Coleman, J. S. M., K. D. Newby, K. D. Multon, and C. L. Taylor, 2014: Weathering the storm: Revisiting severeweather phobia. Bull Amer. Meteor Soc., 95, 1179-1183, Crossref.

Cronbach, L. J., 1951: Coefficient alpha and the internal structure of tests. Psychometrika, 16, 297-334, Crossref.

Davison, K. P., J. W. Pennebaker, and S. S. Dickerson, 2000: Who talks? The social psychology of illness support groups. Amer. Psychologist, 55, 205-217, Crossref.

Delacre, M., D. Lakens, Y. Mora, and C. Leys, 2018: Why psychologists should always report the $\mathrm{W}$-test instead of the F-test ANOVA. PsyArXiv. Available from psyarxiv.com/wnezg.

DePodwin, B., 2018: She looks so happy, how can she be depressed? Available from medium.com/@wx becks/she-looks-so-happy-how-can-she-be-depressedbc1fb024d3da

Egan, P. J., and M. Mullin, 2012: Turning personal experience into political attitudes: The effect of local weather on Americans' perceptions about global warming. J. Politics, 74, 796-809, Crossref

Galton, F., 1865: Hereditary character and talent. Macmillan's Magazine, 12, 157-166. Available from galton.org/ essays/1860-1869/galton-1865-macmillan-hereditarytalent.html

Goldberg, L. R., 1993: The structure of phenotypic personality traits. Amer. Psychologist, 48, 26-34. Available from psych.colorado.edu/ $\sim$ carey/courses/ psyc5112/readings/psnstructure_goldberg.pdf

Goodspeed, R. B., and A. G. DeLucia, 1990: Stress reduction at the worksite: An evaluation of two methods. Amer. $J$. Health Promotion, 4, 333-337, Crossref. 
Greening, L., and S. J. Dollinger, 1992: Adolescents' perceptions of lightning and tornado risks. J. Appl. Social Psychol., 22, 755-762, Crossref.

Hamilton, L. C., and M. D. Stampone, 2013: Blowin' in the wind: Short-term weather and belief in anthropogenic climate change. Wea. Clim, Soc., 5, 112-119, Crossref.

Handmer, J., and B. Proudley: 2007: Communicating uncertainty via probabilities: The case of weather forecasts. Environ. Haz., 7, 79-87, Crossref.

Heinselman, P., D. LaDue, D. Kingfield, and R. Hoffman, 2015: Tornado warning decisions using phased-array radar data. Wea. Forecasting, 30, 57-78, Crossref.

Hoekstra, S., K. Klockow, R. Riley, J. Brotzge, H. Brooks, and S. Erickson, 2011: A preliminary look at the social perspective of warn-on-forecast: Preferred tornado warning lead time and the general public's perceptions of weather risks. Wea. Clim. Soc., 3, 128-140, Crossref.

Joslyn, S., and S. Savelli, 2010: Communicating forecast uncertainty: Public perception of weather forecast uncertainty. Meteor. Apps., 17, 180-195, Crossref.

Lang, F. R., D. John, O. Lüdtke, J. Schupp, and G. G. Wagner, 2011: Short assessment of the Big Five: Robust across survey methods except telephone interviewing. Behav. Res. Methods, 43, 548-567, Crossref.

Levine, T. R., and C. R. Hullett, 2002: Eta squared, partial eta squared, and misreporting of effect size in communication research. Human Comm. Res., 28, 612-625, Crossref.

Lodder, P., 2013: To impute or not impute, that's the question. In J. G. Mellenbergh, and H. J. Adèr (Eds.). Advising on research methods: Selected topics. Huizen: Johannes van Kessel Publishing.

Lonigan, C. J., M. P. Shannon, C. M. Taylor, and A. J. Finch, and F. R. Saller, 1994: Children exposed to disaster: II. Risk factors for the development of posttraumatic symptomatology. J. Amer. Acad. Child Adolesc. Psychiatry, 33, 94-105, Crossref.

Lovibond, S. H., and P. F. Lovibond, 1995: Manual for the Depression Anxiety Stress Scales (second edition). Psychology Foundation.

McCrae, R. R., and P. T. Costa, Jr., 1987: Validation of the five-factor model of personality across instruments and observers. J. Pers. Social Psychology, 52, 81-90, Crossref.

Matthey, S., 1988: Cognitive-behavioral treatment of a thunder-phobic child. Behav. Change, 5, 50-84, Crossref.

Milrad, S., 2016: The mental price of graduate school. Available from shawnmilrad.com/blog

Morss, R. E., J. L. Demuth, and J. K. Lazo, 2008: Communicating uncertainty in weather forecasts: A survey of the U.S. public. Wea. Forecasting, 23, 974991, Crossref.

Nunnally, J. C., 1978: Psychometric Theory. Second edition. McGraw Hill. Available from books.google.com/books/ about/Psychometrictheory.html? id= WE59AAAAMAAJ.
Palmer, S., and W. Dryden, 1994: Stress management: Approaches and interventions. Brit. J. Guid. Counselling, 22, 5-12, Crossref.

Roelfsema, M. T., R. A. Hoekstra, C. Allison, S. Wheelwright, C. Brayne, F. E. Matthews, and S. Baron-Cohen, 2012: Are autism spectrum conditions more prevalent in an information-technology region? A school-based study of three regions in the Netherlands. J. Autism Dev. Disord., 42, 734-739, Crossref.

Rushton, J. P., 1990: Sir Francis Galton, epigenetic rules, genetic similarity theory, and human life-history analysis. J. Personality, 58, 117-140. Available from the Phillipe Rushton Memorial Site: philipperushton. net/w p-content/uploads/2015/02/racegenetic-similarity-galton-rushton-j-ofpersonality-3-1990.pdf

Ruzich, E., C. Allison, B. Chakrabarti, P. Smith, H. Musto, H. Ring, and S. Baron-Cohen, 2015: Sex and STEM occupation predict Autism-spectrum Quotient (AQ) scores in half a million people. PLoS ONE, 10, Crossref.

Sarmany-Schuller, I., 1987: Oscillation of measures of cognitive style (field dependence-independence) in situation of sleep deprivation. Studia Psychologica, 29, 125-132, Crossref.

Steel, P., J. Schmidt, and J. Shultz, 2008: Refining the relationship between personality and subjective wellbeing. Psychological Bull., 134, 138-161. Available at dspace.ucalgary.ca/bitstream/handle/1880/ 47915/Steel Psychological Bulletin 2008 Postprint.pdf? sequence $=1$ \&isAllowed $=\mathrm{y}$.

Stewart, A. E., 2009: Minding the weather: The measurement of weather salience. Bull. Amer. Meteor. Soc., 90, 18331841, Crossref.

Stewart, A. E., J. K. Lazo, R. E. Morss, and J. L. Demuth, 2012: The relationship of weather salience with the perceptions and uses of weather information in a nationwide sample of the United States. Wea. Clim. Soc., 4, 172-189, Crossref.

Taylor, A., W. B. de Bruin, and S. Dessai, 2014: Climate change beliefs and perceptions of weather-related changes in the United Kingdom. Risk Anal., 34, 19952004, Crossref.

The Weather Junkies, 2018: Mental health in meteorology Part 1. Available from theweatherjunkies.com/singlepost/2018/01/31/Mental-Health-in-Meteorology

U.S. Centers for Disease Control, 2018: Autism prevalence slightly higher in CDC's ADDM Network. Available from cdc.gov $/ \mathrm{mmwr} / \mathrm{pdf} / \mathrm{ss} / \mathrm{ss} 6302 . \mathrm{pdf}$

Vogel, D. L., N. G. Wade, S. R. Wester, L. Larson, and A. H. Hackler, 2007: Seeking help from a mental health professional: The influence of one's social network. J. Clin. Psychology, 63, 233-245, Crossref.

Wang, A. G., 2000: Storm phobia: A North Atlantic phenomenon. Nordic J. Psychiatry, 54, 67-68, Crossref. 
Westefeld, J. S, A. Less, T. Ansley, H. S. Yi, 2006: Severe weather phobia. Bull. Amer. Meteor. Soc., 87, 747-749, Crossref.

Wheelwright, S., S. Baron-Cohen, N. Goldenfeld, J. Delaney, D. Fine, R. Smith, L. Weil, and A. Wakabayashi, 2006: Predicting Autism Spectrum Quotient (AQ) from the Systemizing Quotient-Revised (SQ-R) and Empathy Quotient (EQ). Brain Res., 1079, 47-56, Crossref.

Williams, C.A., and A. J. Grundstein, 2017: Children forgotten in hot cars: A mental models approach for improving public health messaging. Injury Prevention, $\underline{\text { Crossref. }}$

Williams, C. A., P. W. Miller, A. W. Black, and J. A. Knox, 2017: Throwing caution to the wind: National Weather Service wind products as perceived by a weather-salient sample. J. Oper. Meteor, 5, 103-120, Crossref.

Wilson, K. A., P. L. Heinselman, and Z. Kang, 2016: Exploring applications of eye-tracking in operational meteorology research. Bull. Amer. Meteor. Soc., 97, 2019-2025, Crossref.

Zee, G., 2017: Natural Disaster: I cover them. I am one. Kingswell. 